\title{
Significant improvement in obese, grade three male individual with nutrient dense low calorie, moderate to high protein diet
}

\begin{abstract}
Nutrient dense, low calorie moderate to high protein diet approach along with introducing a daily activity modification of 45 mints brisk walk intervention approach reduced weight significantly in obese grade $ш$ individual. With a total weight loss of $47 \mathrm{~kg}$ starting from $139 \mathrm{~kg}$ to current weight of $95 \mathrm{~kg} \pm 5 \mathrm{~kg}$ in 12 months starting November 2011 to December 2012, showed improved biochemical clinical reports and retained lean muscle while significant fat loss. Beginning to gradual change in diet and physical activities by introducing 500-700 calorie deficit each day reduced the weight by $500 \mathrm{gm}$ to $1 \mathrm{~kg}$ in a week. Breaking the whole diet into 5-6 small nutrient dense high fiber and moderate to high protein meals keeps the metabolism in speed. Increased soluble fiber and vegetable protein in diet maintained the satiety for a longer time.
\end{abstract}

Volume 2 Issue 2 - 2015

\author{
Ruchi Singh \\ Health counselor \& Nutritionist, Long Island University, USA
}

Correspondence: Ruchi Singh, Health counselor \& Nutritionist, Long Island University, C.W. Post, 44 Lee Avenue Hicksville NY-I I80I, USA, Tel 5166520762, Email ruchi.singh@my.liu.edu

Received: November 17,2014 | Published: March 19, 2015

Keywords: body mass index, basic metabolic rate, obesity, plateau

Abbreviations: BMI, body mass index; REE, resting energy expenditure; PAEE, physical activity related expenditure; TEF, thermic effect of food

\section{Introduction}

Obesity has reached to epidemic level globally due to feasible, palatable, cheap and easily available toxic obeseogenic food which is loaded with sugar, preservatives and saturated fats and physical inactivity. The other reasons of obesity are genetic, medical and psychiatric disorders.

The individual with weight $139 \mathrm{~kg}$ started diet therapy in Nov 2011. Initially the individual was not motivated enough to start a dietary regime. After three to four motivational counseling, he was convinced to start 9 day diet. Motivated by the initial weight loss of $1.3 \mathrm{~kg}$ in 9days he kept on following the diet program for a year with phases of up and downs. Tips and guidance for eating out was given whenever he was out of town or invited for dinner/lunch. Detox diet for a week was suggested whenever individual hits a plateau. After a year individual lost $47 \mathrm{~kg}$ with diet and exercise regime and he is still maintaining his weight in the year 2014.

Obesity, defined as a BMI (Body Mass Index) greater than $30 \mathrm{~kg}$ / $\mathrm{m}^{2}$. Total energy expenditure is the sum of resting energy expenditure (REE), physical activity related expenditure (PAEE) and thermic effect of food (TEF). The human body spends a maximum percentage of calories in REE which depends on lean body mass, age, gender and body temperature. The lean muscle consumes approximately $20 \%$ of REE while adipose tissue consumes only 5\% of REE .Building 1pound of fat contains about 3500 calories. ${ }^{1}$ So, if you created a 500 calorie deficit each day, you'd create a total deficit of 3500 calories per week and should therefore lose about $1 \mathrm{lb}$ of fat per week, moreover calorie expenditure by daily walk of 45 mints create additional 200 $240 \mathrm{kcal}$ deficits. Recommending sessions of strength training while introducing the low calorie, nutrient dense diet, activated muscles all over the body, raising the average daily metabolic rate. Every pound of muscle uses about 6 calories a day just to sustain itself, while each pound of fat burns only 2 calories daily. That small difference can add up over time. Even when calorie balance is resumed, the resting metabolic rate is dependent on the new body mass, especially fat-free mass. $^{2}$

\section{Case description}

This case involves $24 \mathrm{yrs}$ old male, weight $139 \mathrm{~kg}$, Height 5' 6". His BMI was 46.92. He met me for the diet counseling in health and wellness center in the year 2011. He is a business man and life style was sedentary. He put on his maximum weight during his college years when he dependent much on outside food basically burger, pizza and cold drinks. He was suffering from wear and tear of muscles very often during the initial phase of exercise. Weight loss program started with weekly diet and exercise regime. He had a family history of diabetes, hypertension.

In the November of year 2011 he had a knee injury and grade 1 strain on my right leg because of some jumping he did. He checked by an orthopedist and advised for thyroid and normal blood test. The results came was on the borderline of every test. Having family hereditary of diabetes he was afraid that if he become a victim of the family disease.

From the starting he kept on following the diet strictly and was getting results. He was dropping nearly $1 \mathrm{~kg}$ per week. Plenty of options were given to keep the diet therapy interesting and enjoyable. The main focus was on ratio of carbohydrates to protein and the number of meals. Post workout nutrition was also emphasized. Natural herbs like ginger, turmeric, garlic, basil leaves, cinnamon, cloves, nettle leaves was suggested to add in the diet and drinks. Liquids in the form of soups, green tea, smoothies and vegetable juices were added. To provide the bulk and omega 3 in the diet, Chia seeds, flax seeds, sunflower and pumpkin seeds recommended in salad, smoothies or as a snack. 
He started weight training with free weights and cardio on alternate days. After a certain period of time he started with strength training to preserve lean muscles. With the continued change in the diet plans and workouts he rarely hit the plateau.

\section{For this case $i$ focused in five specific areas:}

First was fluid intake, Increasing the fluid intake helps will solve the dual purpose, it suppresses hunger and hydrate body. If you are even mildly dehydrated, your metabolism may slow down. Ingestion of fresh young coconut water, a natural, refreshing beverage, could be used for the whole body rehydration after exercise. ${ }^{3}$

Then, second important factor was controlling the portion size and numbers of meals in a day. Breaking the whole day meal into small meals. Eating more often can help you lose weight. When you eat large meals with many hours in between, your metabolism slows down between meals. Having a small meal or snack every 3 to 4hours keeps your metabolism cranking, so you burn more calories over the course of a day. Several studies have also shown that people who snack regularly eat less at mealtime. Results from the research indicated that a greater number of eating episodes each day were associated with a lower risk of obesity (odds ratio for four or more eating episodes vs. three or fewer $=0.55,95 \%$ confidence interval: $0.33,0.91$ ). In contrast, skipping breakfast was associated with increased prevalence of obesity (odds ratio $=4.5,95 \%$ confidence interval: $1.57,12.90$ ), as was greater a frequency of eating breakfast or dinner away from home. ${ }^{4}$

Third, ratio of carbohydrate to protein. Moderate to high protein diet helps to increase thermogenesis and satiety levels. ${ }^{5}$ High fiber and modest to high protein diet helps to improve the metabolic features such as triglyceride level, fat mass, waist circumstances at the same time $^{6}$ and along with that loss of lean body mass were less. ${ }^{7}$ This diet favorably affects body mass and composition independent of energy intake, which in part supports the proposed metabolic advantage of these diets. ${ }^{8}$ The body burns many more calories digesting protein than it does eating fat or carbohydrates. As part of a balanced diet, replacing some carbohydrates with lean, protein-rich foods can boost metabolism at mealtime. Good sources of protein include lean beef, turkey, fish, white meat chicken, tofu, nuts, beans, eggs and low-fat dairy products.

Fourth, quantity and quality of oil and fat, total recommended quality of oil/ fat was 25-30 gm and canola or olive choice was given. As the fat provides more calories per gram, provide less satiation promotes over consumption and is more readily absorbable from the intestine, cutting down the quantity of visible and invisible fat would help with weight loss. ${ }^{9}$

Fifth, using specific supplements. I recommended $250 \mathrm{mg}$ of vitamin $\mathrm{C}$ as Vitamin $\mathrm{C}$ status is inversely related to body mass. Individuals with adequate vitamin $\mathrm{C}$ status oxidize $30 \%$ more fat during a moderate exercise bout than individuals with low vitamin $\mathrm{C}$ status; thus, vitamin $\mathrm{C}$ depleted individuals may be more resistant to fat mass loss. Food choices can impact post-meal satiety and hunger. High-protein foods promote postprandial thermogenesis and greater satiety as compared to high-carbohydrate, low-fat foods; thus, diet regimens high in protein foods may improve diet compliance and diet effectiveness. Vinegar and peanut ingestion can reduce the glycemic effect of a meal, a phenomenon that has been related to satiety and reduced food consumption. Thus, the effectiveness of regular exercise and a prudent diet for weight loss may be enhanced by attention to specific diet details. ${ }^{10}$
Eating spicy foods have natural bio-chemicals that stimulate the metabolism into a higher gear. Cooking foods with a tablespoon of chopped red or green chili pepper and turmeric can boost your metabolic rate. Adding garlic paste or cloves helps in reducing blood pressure. ${ }^{11}$ Garlic also helps in reducing the blood sugar level and triglycerides. ${ }^{12}$ The effect is probably temporary, but if you eat spicy foods often the benefits may add up.

As the obesity leads to metabolic disorders like diabetes, dyslipidemia etc. Scientific research showed the multiple benefits of taking Coenzyme q10 in preventing those metabolic disorders develop due to obesity. Research provided a new insight into the possible mechanisms by which CoQ10 improves insulin sensitivity and adjusts type 2 diabetic disorder. These mechanisms involve modulation of insulin and improving lipid profile, this study also points to the potential positive effect of $\mathrm{CoQ} 10$ as an adds on to conventional antidiabetic therapies. ${ }^{13}$ Coenzyme Q10 (Co-Q10) is a mitochondrial component involve in electron transport chain reaction. Cells involve in higher activity are sensitive to co-enzyme Q10 (Co-Q10) deficiency. This deficiency has been implicated in several clinical disorders such as heart failure, hypertension, Parkinson's disease and obesity. Recent evidence suggests that Co-Q10 supplementation may be useful for the treatment of obesity, oxidative stress and the inflammatory process in metabolic syndrome. ${ }^{14}$ Coffee taken in moderation, boost metabolic rate for a short time. Caffeine can help you feel less tired and even increase your endurance while you exercise. ${ }^{15}$

\section{Methodologies}

The Gradual intervention of nutrient dense, low calorie diet modification with a reduced ratio of carbohydrates to protein and physical activity intervention of brisk walk combined with weight training for 45 minutes every day. Body weight recorded once in a week in a progress record and body measurement once in a month.

\section{Result}

Maintained weight loss of $47 \mathrm{~kg} \pm 5$ with improved total body composition outcome at 12 months. Average weight loss Rate: $3.9 \mathrm{~kg} /$ month. Current is BMI $32.10 \mathrm{~kg} / \mathrm{m}^{2}$ (grade 2 obesity). Body composition checked by "in body 230 (prospectheightschiropractor. com/weight-loss.html) machine once a month. ${ }^{16}$

\section{Discussion}

Future long term research warranted to understand the effectiveness of diet therapy for long term maintenance of healthy weight. Weight loss rate in an individual with metabolic disorder might need a different approach. Along with diet, activity therapy some medical intervention might require.

\section{Conclusion}

Individualized and customized low calorie moderate to high protein dietary therapy with activity modification and regular motivation effectively reduced the weight of morbidly obese individuals. Regular interaction and plenty of food choices and advices kept the individual motivated to achieve the set target. Improved body composition and body measurement along with compliments and encouragement from the friend and family made this individual to achieve this milestone.

\section{Acknowledgements}

None. 


\section{Conflict of interest}

The author declares no conflict of interest.

\section{References}

1. Ross A Catharine. Modern nutrition in health and disease. In: Shils ME, Shike M, editors. USA: Lippincott Williams \& Wilkins; 2006.

2. Vanhecke TE, Franklin BA, Lillystone MA, et al. Caloric expenditure in the morbidly obese using dual energy $\mathrm{X}$-ray absorptiometry. J Clin Densitom. 2006;9(4):438-444.

3. Saat M, Singh R, Sirisinghe RG, et al. Rehydration after exercise with fresh young coconut water, carbohydrate-electrolyte beverage and plain water. J Physiol Anthropol Appl Human Sci. 2002;21(2):93-104.

4. Ma Y, Bertone ER, Stanek EJ, et al. Association between eating patterns and obesity in a free-living US adult population. Am J Epidemiol. 2003;158(1):85-92.

5. Halton TL, Hu FB. The effects of high protein diets on thermogenesis, satiety and weight loss: a critical review. J Am Coll Nutr. 2004;23(5):373385 .

6. McAuley KA, Smith KJ, Taylor RW, et al. Long-term effects of popular dietary approaches on weight loss and features of insulin resistance. Int $J$ Obes. 2005;30(2):342-349.

7. Leidy HJ, Carnell NS, Mattes RD, et al. Higher protein intake preserves lean mass and satiety with weight loss in pre-obese and obese women. Obesity. 2007;15(2):421-429.
8. Krieger JW, Sitren HS, Daniels MJ, et al. Effects of variation in protein and carbohydrate intake on body mass and composition during energy restriction: a meta-regression 1. Am J Clin Nutr. 2006;83(2):260-274.

9. Astrup A. The role of dietary fat in the prevention and treatment of obesity. Efficacy and safety of low-fat diets. Int $J$ Obes Relat Metab Disord. 2001;25(Supply1):46-50.

10. Johnston CS. Strategies for healthy weight loss: from vitamin $\mathrm{C}$ to the glycemic response. J Am Coll Nutr. 2005;24(3):158-165.

11. Ried K, Frank OR, Stocks NP, et al. Effect of garlic on blood pressure: a systematic review and meta-analysis. BMC Cardiovasc Disord. 2008;8:13.

12. Thomson M, Al Amin ZM, Al Qattan KK, et al. Anti-diabetic and hypolipidaemic properties of garlic (Allium sativum) in streptozotocininduced diabetic rats. Int J Diabetes \& Metabolism. 2007;15:108-115.

13. Amin MM, Asaad GF, Salam RMA, et al. Novel CoQ10 Antidiabetic Mechanisms Underlie Its Positive Effect: Modulation of Insulin and Adiponectine Receptors, Tyrosine Kinase, PI3K, Glucose Transporters, sRAGE and Visfatin in Insulin Resistant/Diabetic Rats. PloS one. 2014;9(2):e89169.

14. Alam MA, Rahman MM. Mitochondrial dysfunction in obesity: potential benefit and mechanism of Co-enzyme Q10 supplementation in metabolic syndrome. J Diabetes Metab Disord. 2014;13:60

15. Bakuradze T, Parra GAM, Riedel A, et al. Four weeks coffee consumption affects energy intake, satiety regulation, body fat and protects DNA integrity. Food Research International. 2014;63:420-427.

16. http://prospectheightschiropractor.com/weight-loss.html 